\title{
Research on the Construction of Information Sharing Space of University Library Aiming for the Construction of Key Disciplines
}

\author{
Qingsong Zhang ${ }^{1, \text { a }}$ \\ ${ }^{1}$ Library, Jilin Agricultural University, Changchun,130118, China \\ aemail:729738677@qq.com
}

Key words: Key disciplines, Information sharing space, Disciplinary Services

\begin{abstract}
Through the analysis of the background and current situation of the information sharing space and the subject service, it is proposed that the construction of the library information sharing space based on the construction of key disciplines is an important transformation and service innovation of the university library development under the network environment. Combined with the actual situation of zootechnics, a zootechnics information sharing space service model is designed and built from the perspective of disciplinary services.
\end{abstract}

\section{Introduction}

The construction of key disciplines has become the future development direction of library service mode. It takes user demand driver as the center and aims to build the information security environment which is adapt to users' personalized information needs. It organically embeds the subject information services and information resources in the users' physical space and virtual environment providing users with one-stop intensive information services as well as the new operating mechanism like system architecture, institutional adjustment, service upgrades, resource allocation. In this kind of active exchange of information exchange mode, the library's resources and services become an important part of user information activities. Information services achieve the ubiquity and availability of the service from the hidden, scattered, and free to dominance, concentration, and precipitation. To enhance the status and influence of the library in teaching and research reflects the social mission and service essence of the library.

\section{Planning and Designing of Library 's Subjective Information Sharing Space}

Based on the background of the information sharing space, the core concept and the characteristics of zootechnics, the paper puts forward the conceptual model of information sharing space for the construction of special disciplines based on the theories of library science, knowledge management, informatization and so on. It can be described by the three levels: entity layer, virtual layer and service layer.

\subsection{Construction of the Physical Layer of Information Sharing Space Based on Key Disciplines}

The physical layer in the information sharing space refers to the physical place where the user is used to learn, communicate and move, including physical space, hardware facilities, human resources and other aspects. It is composed of individual learning area, group unity and cooperation area, open learning area, multimedia production area, open access area, the exchanging area of guiding users to learn and improve skills, collaborative experimental area, recreation area and other regional composition. Hardware facilities include a variety of computer equipments, reference desk, multimedia technology support desk and other facilities. Human resources personnel include disciplinary experts, disciplinary librarians, network engineers, student assistant and so on. The physical layer is built by following the principle of "changing in accordance with needs" and strives for creating a beautiful environment which is suitable for learning, communication, 
collaboration and "one-stop" service function for teachers and students.

\subsection{Construction of the Virtual Layer of Information Sharing Space Based on Key Disciplines}

The virtual layer in the information sharing space is the virtual place where the user is used to learn, communicate and share knowledge which includes virtual space, information resources and software facilities and other parts.

Organization of information resources

Relying on the regional characteristics of Jilin Province, the characteristics of zootechnics and library collections of Jilin Agricultural University, the special animal information resources existing in different time and space are digitally collected and conversed. (1) Converse the paper books into graphic database data for storage by using the optical character recognition technology and image processing technology. (2) Select and record books about zootechnics and their catalogs in electronic databases such as reading show, superstar book, scholar book and so on. Generate animal husbandry digital library bibliography and catalogs and establish links. (3) Download the articles on livestock-related information and articles in the livestock professional journals contained in the full-text database. (4) Use searching tools to retrieve information related to livestock and conduct classification and storage on the Internet. (5) Subject librarians should visit the experts and scholars, universities, and enterprises in the field of livestock collecting first-hand information and counting statistical data and other information resources. The corresponding content of zootechnics in the Livestock Discipline Digital Library can be divided into three sub-libraries: animal husbandry knowledge base, animal husbandry teaching library, animal husbandry science and technology library, which function as following: (1)To achieve the creation and deletion of data, information retrieval and publishing, user management, system maintenance and other functions. (2) The three main sub-library of digital library can not only be used alone, but also achieve the cross-database search of the image text information. (3) Users can provide topics, authors, titles, keywords, types and other conditions and conduct a simple and advanced search at the same time. (4)Perfect data update mechanism.

Software facilities

In order to ensure effective support of the access and use of information resources, it has become the most advanced information technology experience and the place for disciplines exploration to protect the software facilities in information sharing space including professional software, the software tools for the access to information, office automation tools, multimedia player software, graphics processing tools, document management software, electronic resource management and using software, etc. and to ensure the timely update of the software and ensure the information sharing space.

Construction of Virtual Environment of Subject Information Sharing Space

Based on the embedded disciplinary services of the virtual space can break through the limitations of time and space, users can enjoy the visible, convenient, efficient service with high quality in the human-computer interaction. There are several service modes: (1) The information resources and academic services of the library are embedded in the iPad, mobile phones, learning machines, readers and other intelligent devices. Based on the high penetration rate of the above equipments, their characteristics like portable and versatile make the handheld reading work like new book notification, reference consulting, borrowing information query, database search possible. A high degree of real learning and portable can also be achieved. (2) Conduct the personalized push service of RSS. Adopt RSS polymerization subject information with web2.0 technology and push the library subject information and special information to the user's computer desktop according to the user's personality needs. (3) Establish subjects Blog and Discipline QQ group and create interactive academic community to guide readers to communicate and feedback in the interaction. (4) The shortcut menu embedded in the user's common software and website, so that users can still easily enjoy the library services even though they do not log library site. 


\section{Construction of Information Sharing Space Service Layer Based on Key Disciplines}

The service layer is the power layer and guarantee layer of the operation and development of the information sharing space. The operation and development of the information sharing space need the organic integration of the service layer to drive and support the physical layer and the virtual layer. Information technology, service norms, operating mechanism, evaluation system and other parts of the space protect the scientific operation and development of various systems, links, and personnel.

\subsection{The organization of information sharing space}

University library should be user - centered, form user - driven service concept, and plan the theoretical services, top - level design and service processes of the academic system. Grasp the characteristics and trends of user needs, staff changing, and organization. Re-plan information resource layout and build the information sharing space which combines physical space and virtual space. The positive chief building team is essential for the construction of information sharing space. The support of the school authorities and the institutionalization of discipline service work are the important guarantee for the success of the normalization of activities. Seek cooperation with other information service agencies. Promote discipline services together under the principle of mutual benefit. Strengthen the unity and cooperation of various departments and build a positive and progressive organizational culture. Strengthen exchanges and communication and enhance the overall level of academic services based on functional collaboration. Coordinate all forces in accordance with the concept of service-oriented and develop all-round discipline services work.

\subsection{The serving standard of disciplinary Information Sharing Space}

The digital processing, resource description and organization in the process of constructing information sharing space should obey the related standards of "China Academic Library \& Information System (CALIS) digital library construction standards and norms", "Image data processing standards and work norms", "Journal of Metadata Specification", "Electronic Continuity Resource Metadata Specification", and "Network Resource Metadata Specification". Standardize the construction of information sharing space, so that the high-quality of digital resources can be functioned in a long term.

\subsection{Evaluation System of Subject Information Sharing Space}

From the four aspects of accessibility, service experience, the library environment, the user personal control of information resources, carry out the evaluation on $f$ the user-centered information sharing space service model. Be familiar with users' feedback timely. Use daily feedback, advice box feedback, questionnaires, online surveys and other methods to understand the needs of users and suggestions for improved work advice. Form a true user service mechanism and achieve the value of the library itself in the process of providing users with efficient, high-quality, personalized, and deep disciplines service.

\subsection{The service means of information sharing space}

Use information and communication technology to build a computer operating environment and user communication platform for users to provide information resources navigation and strengthen communication and interaction between users, such as BBS、RSS、QQ、BLOG、E-mail. Enhance the systematicness and real - time of subject service. Mobile technology can improve the efficiency and value of library services and resources. The integration strategy can complete multiple searches of information between knowledge and heterogeneous databases. Data mining technology can find out the deep value of knowledge resources through the daily circulation of data analysis and processing. Through the use of information and communication technology to excavate, store, process, publish knowledge resources, effectively integrated into the user's teaching and research environment. Carry out the discipline service work in a targeted and purposeful way and enhance the library's overall service level. 


\section{Acknowledgements}

In this paper, the research was sponsored by the Project of Jilin Province Science of Education "12th five-year" planned project "Construction and Implementation of University library Resources and Service Support Platform for Key Subjects"(GH150212), and The "13th five-year" social science research project of the Education Department of Jilin Province, named" A Study on Construction of Information Commons in University Library for Major Subject Construction "(2016139).

\section{References}

[1] Ren Shuhuai. Research on Information Sharing Space, System Architecture and Practice. [J]. Digital Library Forum, 2009,(2):1-12.

[2] Duan Dan. Practical Exploration of the Disciplinary Service of Libraries in Finance and Economics Colleges and Universities - Taking Dongbei University of Finance and Economics as an Example. [J]. 2013,(3):55-56.

[3] Wang Yujing. Practice and Reflection on the Disciplinary Service of Teaching University Libraries. [J]. Information studies:Theory \& Application, 2012,(9):95-97.

[4] Yang Zhiping, Zhong Yongheng, Wu Ming. Institutionalized collaborative development model, [J]. Library and Information Service, 2012,(3):10-14.

[5] Wang Yunxiang, Wu Jiegou. Discussion on Several Problems in Constructing the Service Mode of Subjective Information Sharing Space. [J]. Library and Information, 2012,(6):112-115.

[6] luo Xiujuan. Construction of Subject Information Sharing Space 2.0 Service Mode. [J]. Library and Information, 2013,(3):94-97. 